\title{
miRNA-regulated gene expression differs in celiac disease patients according to the age of presentation
}

\author{
Gaia Buoli Comani ${ }^{1} \cdot$ Roberto Panceri $^{2} \cdot$ Marco Dinelli $^{3} \cdot$ Andrea Biondi $^{1,2}$. \\ Clara Mancuso $^{1} \cdot$ Raffaella Meneveri $^{1} \cdot$ Donatella Barisani $^{1}$
}

Received: 18 April 2015/Accepted: 17 July 2015/Published online: 2 August 2015

(C) Springer-Verlag Berlin Heidelberg 2015

\begin{abstract}
Celiac disease is an intestinal disease which shows different symptoms and clinical manifestations among pediatric and adult patients. These variations could be imputable to age-related changes in gut architecture and intestinal immune system, which could be characterized by gene expression differences possibly regulated by miRNAs. We analyzed a panel of miRNAs and their target genes in duodenal biopsies of Marsh $3 \mathrm{AB}$ and $3 \mathrm{C}$ pediatric celiac patients, compared to controls. Moreover, to assess variation of expression in plasma samples, we evaluated circulating miRNA levels in controls and patients at diagnosis or on gluten-free diet. We detected a decreased miR$192-5 p$ expression in celiac patients, but no variations in NOD2 and CXCL2, targets previously identified in adults. Conversely, we detected a significant increase in mRNA and protein levels of another target, MAD2L1, protein related to cell cycle control. miR-31-5p and miR-338-3p were down-regulated and their respective targets, FOXP3 and RUNX1, involved in Treg function, resulted up-regulated in celiac patients. Finally, we detected, in celiac patients, an increased expression of miR-21-5p, possibly
\end{abstract}

Electronic supplementary material The online version of this article (doi:10.1007/s12263-015-0482-2) contains supplementary material, which is available to authorized users.

Donatella Barisani

donatella.barisani@unimib.it

1 Department of Health Sciences, School of Medicine, University of Milano-Bicocca, Via Cadore, 48, 20900 Monza, MB, Italy

2 Fondazione MBBM, Azienda Ospedaliera S.Gerardo, Monza, Italy

3 Unità Endoscopia Digestiva, Azienda Ospedaliera S.Gerardo, Monza, Italy caused by a regulatory loop with its putative target STAT3, which showed an increased activation in Marsh 3C patients. The analysis of plasma revealed a trend similar to that observed in biopsies, but in presence of gluten-free diet we could not detect circulating miRNAs values comparable to controls. miRNAs and their gene targets showed an altered expression in duodenal mucosa and plasma of celiac disease pediatric patients, and these alterations could be different from adult ones.

Keywords Celiac disease - Pediatrics - MicroRNA . Immunity

\section{Introduction}

Celiac disease (CD) is an inflammatory disease of the small intestine affecting at least $1 \%$ of world population, with an increase in incidence, in particular considering children (Kenrick and Day 2014). The clinical symptoms of CD are variable and differ according to the age of presentation (Diamanti et al. 2014). Adults patients can have intestinal and extra-intestinal clinical manifestations, whereas children often present CD with "classic" symptoms including abdominal pain, malabsorption and growth retardation (Telega et al. 2008). CD is triggered by the ingestion of gluten peptides in genetically predisposed individuals; this fact starts a cascade of events involving immune response, which results in intestinal damage and increase in intestinal permeability (Schuppan et al. 2009).

The major genetic risk factor identified up to now is the presence of a specific HLA heterodimer, namely DQ2.5 [DQA1*0501-DQB1*0201] (either in cis or trans position), or DQ8 [DQA1*03-DQB1*0302/0305] haplotypes; the presence of the various combination of different 
haplotypes allows also to categorize subjects with a moderate (single DQ2.5 or DQ8) or a high risk of celiac disease (homozygosity for DQA $1 * 0501-\mathrm{DQB} 1 * 0201$ or DQA $1 * 0501-D Q B 1 * 0201$ and DQA $1 * 0201-D Q B 1 * 02$ ) (Romanos et al. 2014). Genome-wide association studies have identified several additional loci (mostly including genes related to the immune response), but in total only $50 \%$ of the genetic predisposition can be accounted for (Dubois et al. 2010; Gutierrez-Achury et al. 2015). The presence of a genetic risk is, however, not sufficient for the development of the disease, since interaction with gluten is essential. The difference in the time of development had been hypothesized to depend upon the age of gluten introduction in the diet, but recent multicentric studies in high-risk children have demonstrated that the delayed introduction of gluten in the diet can have only a slight effect, since at 5 years of age the prevalence of autoantibody positivity or of $\mathrm{CD}$ was similar in the early versus late gluten introduction group (Lionetti et al. 2014; Vriezinga et al. 2014).

The development of $\mathrm{CD}$ either in children or adults could thus be associated with a different immune response to gluten (rather than the age of introduction), possibly due to the maturation of the intestinal immune system or its abnormal regulation. Thus processes regulating immunity, at transcriptional and post-transcriptional level, could affect the clinical manifestation and the severity of the disease. A pivotal role could be played by microRNAs (miRNAs), a class of small non-coding RNAs, which bind the complementary sequences in the $3^{\prime} \mathrm{UTR}$ of target genes causing their degradation or translational inhibition (Runtsch et al. 2014). We previously focused our attention on the role of miRNAs in the regulation of gene expression in $\mathrm{CD}$, reporting a microarray analysis performed on adult CD patients with different phenotypes (Vaira et al. 2014) and we also described the different expression of some miRNAs and their target genes, involved in the immune response, according to the severity of the intestinal lesion (Magni et al. 2014). However, we obtained these data in adult patients, and the same miRNAs identified by us as down-regulated in adult CD had not been previously detected as altered in biopsies obtained from CD children (Sapone et al. 2011). There are very few data on the morphological and histological differences in small intestinal architecture at different ages (Ren et al. 2014), and on the development of the immune response in intestine (Mabbott et al. 2015), and no data on miRNA profile that could be different according to age.

Moreover, although diagnostic criteria for pediatric CD have been recently revised (Husby et al. 2012; Giersiepen et al. 2012), additional markers could be useful in $\mathrm{CD}$ diagnosis in children with various clinical manifestations or in follow-up. A panel of miRNAs differently expressed in the serum of CD patients could thus be used as molecular biomarkers. To assess whether the miRNAs and targets identified in adults as differentially expressed, presented the same pattern in children, we evaluated a cohort of pediatric $\mathrm{CD}$ patients and analyzed miRNA levels in the serum at diagnosis and in patients on gluten-free diet (GFD) to verify whether they could also represent a good indicator of compliance and mucosal recovery.

\section{Materials and methods}

\section{Patients' cohorts}

Duodenal biopsies were obtained from a total of 28 children, who underwent upper gastrointestinal endoscopy for diagnostic purposes, after having obtained the informed consent from their parents. Analyses were performed on 8 controls (subjects with normal endoscopic and histological duodenal findings, 4 girls and 4 boys, mean age $11 \pm 3.8$ years) and 20 patients with untreated CD (11 girls and 9 boys, mean age $8 \pm 3.6$ years), divided into Marsh 3AB (either with Marsh 3A or Marsh 3B) and Marsh $3 \mathrm{C}$ group ( 8 and 12 patients, respectively) (Oberhuber 2000) in whom diagnosis was based on positive anti tTG and/or anti-endomysium antibody testing and duodenal histology. Duodenal biopsies were frozen for RNA isolation and protein extraction and maintained at $-80^{\circ} \mathrm{C}$ until use. For experiments on plasma, we enrolled a total of 36 subjects: 12 controls ( 6 girls and 6 boys, mean age $10 \pm 3.6$ years) and $17 \mathrm{CD}$ patients (7 Marsh $3 \mathrm{AB}$ and 10 Marsh 3C, 9 girls and 8 boys, mean age $7 \pm 3.4$ years) at the first diagnosis (13 of them were the same subjects undergoing biopsy) and additional $7 \mathrm{CD}$ patients (4 girls and 3 boys, mean age $9 \pm 4.3$ years) on GFD for at least 1 year. Blood samples were immediately centrifuged at $3000 \mathrm{~g}$ to obtain plasma fractions, which were aliquoted and stored at $-80{ }^{\circ} \mathrm{C}$ until use. No statistically significant difference in demographic parameters was observed between the groups (Table 1S).

As assessed by the diagnostic guidelines of ESPGHAN, HLA typing is not required for CD diagnosis. However, HLA typing was performed in $20 \mathrm{CD}$ patients; 19 subjects resulted DQ2 positive and one DQ8 (15 first diagnosis patients and 5 on GFD).

For miR-486-5p and MAD2L1, the data obtained in the children cohorts were compared to those observed in the previously analyzed adult cohorts (Magni et al. 2014).

The study was approved by the pertinent ethics committee of San Gerardo Hospital-Monza (MB) and it is conformed to the standards set by the Declaration of Helsinki. 


\section{RNA extraction}

Total RNA was extracted from biopsies using a MiRcury RNA Isolation Kit (Exiqon, Vedbaek, Denmark) following the manufacturer's instructions. Total RNA extraction from plasma was performed using miRNeasy Serum/Plasma Kit (Qiagen, Valencia, CA) and following the manufacturer's instructions. Quality and quantification of extracted RNA was performed by NanoDrop 1000 Spectrophotometer (Thermo Scientific, Waltham, MA, USA).

\section{RT-qPCR}

qPCR was performed using 7900HT Fast Real-Time PCR System (Applied Biosystems-Life Technologies, Carlsbad, CA, USA). For miRNAs analyses, RNA was reverse transcribed using TaqMan MicroRNA Reverse Transcription kit (Applied Biosystem), and the commercial available kit TaqMan MicroRNA Assays (Applied Biosystem) were used for quantitative PCR. Identification of miRNAs' possible targets was performed using the following softwares and databases: mirTarBase (http://mirtarbase.mbc. nctu.edu.tw/), Targetscan (http://www.targetscan.org/), microRNA.org (http://www.microrna.org/microrna/home. do) and Mirò (http://ferrolab.dmi.unict.it/miro/), considering their miR SVR score, focusing in particular on those with an in vitro validation.

For gene expression, instead, TaqMan Reverse Transcription Reagents kit (Applied Biosystems) was used with random primers to obtain cDNAs, and Sybr green PCR Master Mix (Applied Biosystems) was employed for the detection of target mRNAs with the exception of FOXP3 and MAD2L1 (assessed by TaqMan Gene Expression Assay, Applied Biosystem). Primers were designed to be intron spanning to avoid co-amplification of genomic DNA, and no signal was detected when un-retrotranscribed RNA was used as template:

NOD2 (FORWARD: 5'-GCTGCCTTCCTTCTACA ACA-3', REVERSE: 5'-GCGTCTCTGCTCCATCATA G-3')

CXCL2 (FORWARD: 5'-CTCAAGAATGGGCAGAAA

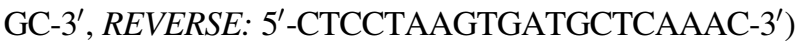
RUNX1 (FORWARD: 5'-GCAGCGTGGTAAAAGAA ATC-3', REVERSE: 5'-GTGGAAGGCGGCGTGAAGC G-3')

STAT3 (FORWARD: 5'-TGGTGTTTCATAATCTCCT

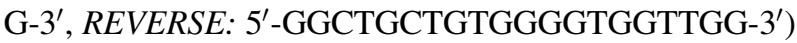
GAPDH (FORWARD: 5'-TGGTAAAGTGGATATTG TTGCC-3', REVERSE: 5'-GGTGAAGACGCCAGTGGAC- $3^{\prime}$ )

For all analyses, each sample was examined in triplicate. All data were normalized to the Let- $7 \mathrm{~b}$ for miRNA analysis and to GAPDH (glyceraldehyde-3-phosphate dehydrogenase) for genes. The relative quantification with $2^{(-\Delta \Delta \mathrm{Ct})}$ method was employed to calculate relative changes in gene expression using an external reference sample (RNA obtained from duodenal biopsies of a control subject, not included in the analysis).

\section{Western blot analysis}

Protein extraction was performed with RIPA buffer containing protease and phosphatase inhibitors (SigmaAldrich, St. Louis, MO, USA), after having disrupted manually duodenal tissues. Proteins were separated on NuPAGE Novel Bis-Tris (4-12 \%) gels (Invitrogen-Life Technologies, Carslbad, CA, USA). They were transferred on nitrocellulose membrane (Amersham, Buckinghamshire, UK). Membranes were blocked with TTBS and $5 \%$ non-fat milk and hybridizations performed at $4{ }^{\circ} \mathrm{C}$ overnight with the following antibodies: mouse anti-human NOD2 (Anti-CARD15 antibody [2D9]—ab31488, Abcam, 1:1000) (Abcam, Cambridge, UK), goat anti-human CXCL2 (Anti-GRO beta antibody-ab91511, Abcam, 1:2000), mouse anti-human FOXP3 (Anti-FOXP3 antibody-ab22510, Abcam, 1:500), mouse anti-human MAD2L1 (WH0004085M1, Sigma-Aldrich, $1: 1000+2 \%$ milk), rabbit anti-human phospho-STAT3 (ser727) (\#9134, Cell Signalling, 1:1000) (Cell Signalling, Danvers, MA, USA), and rabbit Anti-human actin (A2066, Sigma, 1:1500). SuperSignal West Pico Chemiluminescent Substrate (Thermo Scientific) was used to visualize the signal. Quantification of signal was performed with a FluorS Multilmager using the Quantity One 4.1.1 Software Package, both from Bio-Rad (Milan, Italy).

\section{Statistical analysis}

ANOVA and Student's $t$ test was performed for the comparison of the data. ANOVA on ranks followed by Dunn post hoc test was used when data failed the equal variance test. The significance level was set at $p$ value $<0.05$. Statistical evaluation was performed with the SYSTAT software package (SPSS, Chicago, IL).

\section{Results}

We initially analyzed some miRNAs previously detected as differentially expressed in the duodenum of $\mathrm{CD}$ adult patients compared to controls (Magni et al. 2014).

miR-192-5p expression was significantly reduced in biopsies obtained from $\mathrm{CD}$ patients, with a more profound decrease in Marsh $3 C$ patients $(0.90 \pm 0.32$ vs $0.59 \pm 0.39$ and $0.47 \pm 0.34$ in controls, Marsh $3 \mathrm{AB}$ and Marsh $3 \mathrm{C}$, 
respectively, $p=0.013$ by ANOVA) (Fig. 1). We also studied the expression of chemokine (C-X-C motif) ligand 2 (CXCL2) and nucleotide-binding oligomerization domain containing 2 (NOD2), validated targets of miR$192-5 p$ in adults. Differently from what expected, the expression of these molecules did not inversely correlate
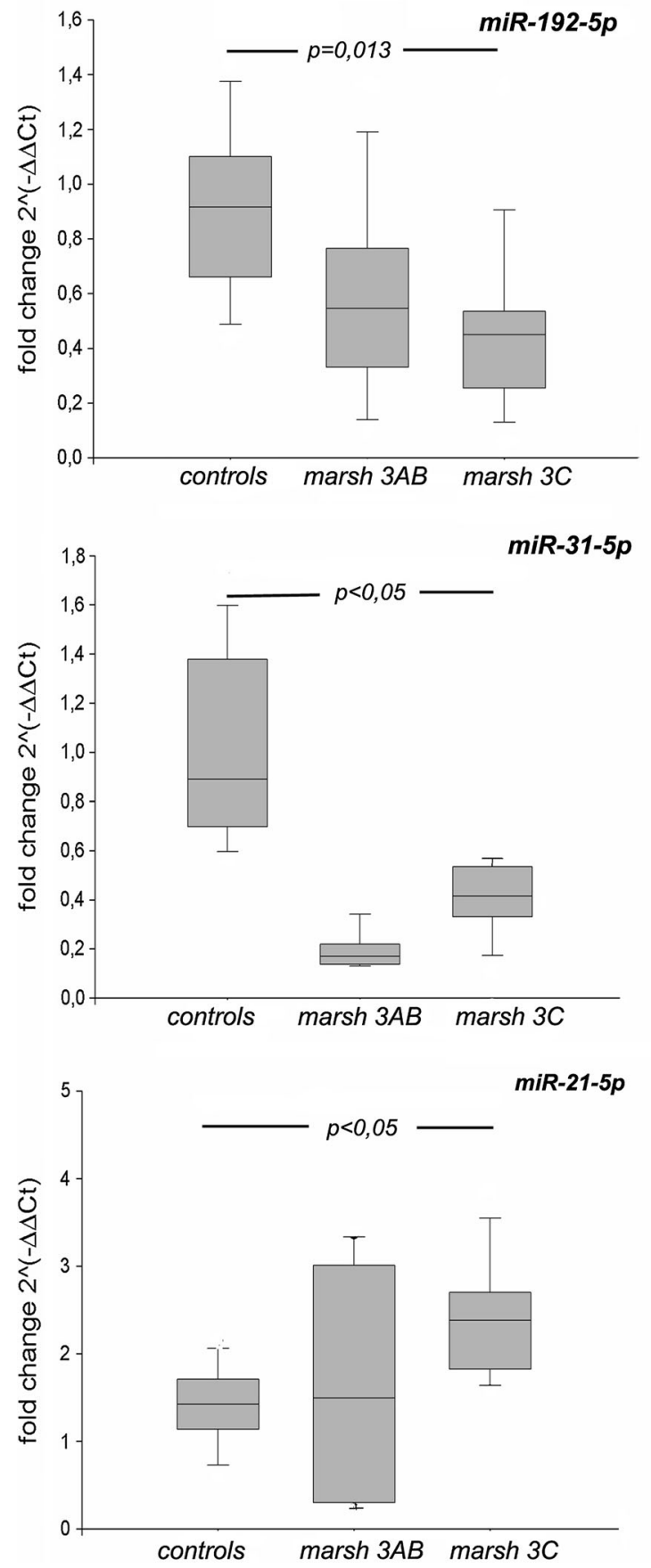

Fig. 1 miRNAs expression. Expression level of miR-192-5p, miR31-5p, miR-338-3p, miR-21-5p, miR-21-3p and miR-486-5p in duodenal biopsies of controls $(n=8)$, Marsh $3 \mathrm{AB}(n=8)$ and Marsh 3C $(n=12)$ celiac pediatric patients. Data obtained by with miR-192-5p levels: CXCL2 mRNA expression was significantly reduced in biopsies obtained from Marsh 3C patients $(0.32 \pm 0.20$ vs $0.20 \pm 0.15$ and $0.10 \pm 0.07$ in controls, Marsh 3AB and Marsh 3C, respectively, $p<0.05$ by ANOVA), whereas protein expression in controls and marsh $3 \mathrm{C}$, did not show any variations $(0.43 \pm 0.11$ vs
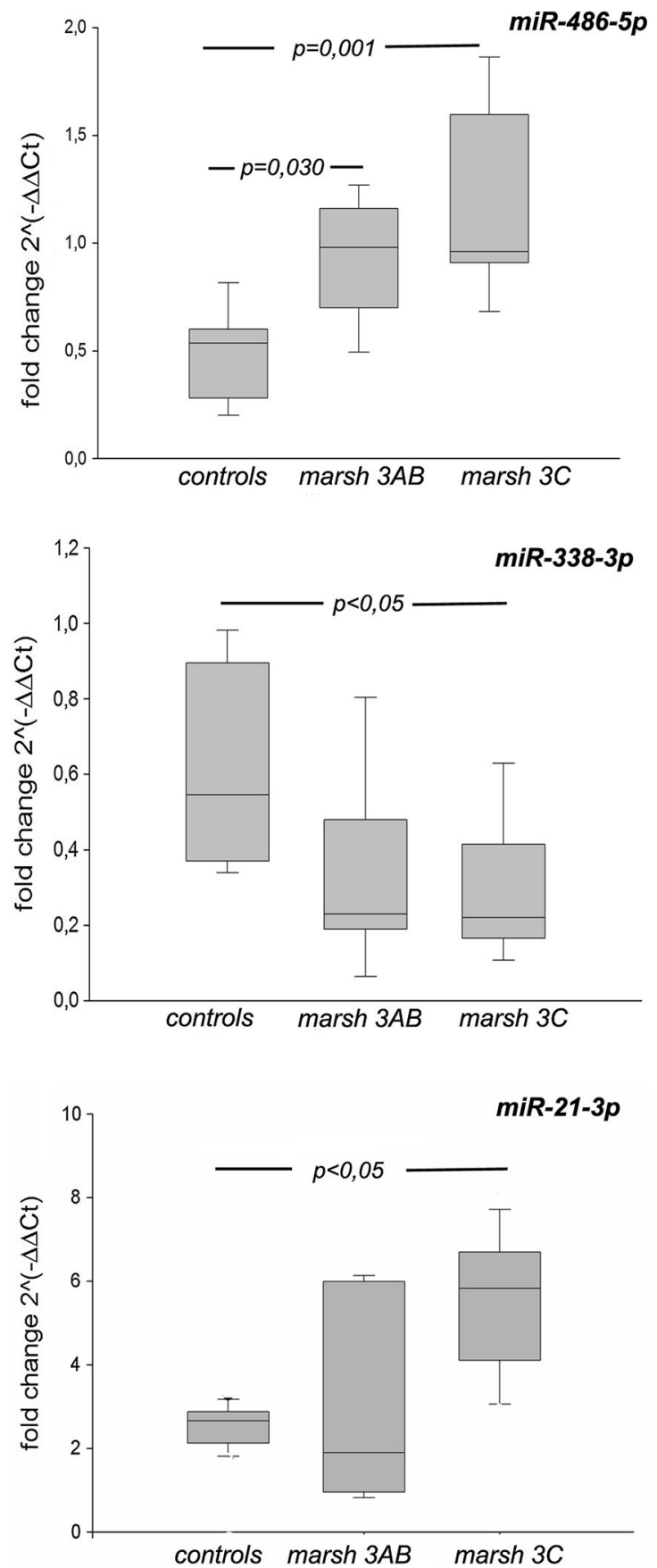

quantitative PCR are represented as fold change compared to an external sample. The box plots show median value and the 25 and 75 percentiles, whiskers the maximum and minimum value. Statistical analysis was performed by one-way ANOVA 
$0.52 \pm 0.30$, controls and Marsh $3 \mathrm{C}$, respectively, $p=\mathrm{ns}$ by $t$ test). Moreover, NOD2 mRNA levels in children were unchanged in $\mathrm{CD}$ groups compared to controls $(0.17 \pm 0.15$ in controls, $0.40 \pm 0.45$ in Marsh $3 \mathrm{AB}$ and $0.20 \pm 0.19$ in marsh $3 \mathrm{C}$, respectively) as well as NOD2 protein expression $(0.44 \pm 0.20$ vs $0.60 \pm 0.59$ in controls and Marsh 3C, respectively).

Several miRNAs can bind the same mRNA and the final effect is due to the balance among them. To assess whether other miRNAs could bind NOD2 and CXCL2, we performed in silico analyses that identified miR-486-5p seeding sequence within their $3^{\prime}$ UTR. This miRNA was significantly up-regulated in pediatric CD patients compared to controls $(0.49 \pm 0.23, \quad 0.93 \pm 0.31$ and $1.17 \pm 0.47$ in controls, Marsh $3 \mathrm{AB}$ and Marsh $3 \mathrm{C}$, $p=0.030$ and $p=0.001$, respectively, by ANOVA) (Fig. 1) but not in adult ones $(1.13 \pm 0.82$ and $1.05 \pm 0.78$ in controls and Marsh 3C patients, respectively, data not shown), thus supporting the presence of a different miRNA-regulatory pattern.

In silico analysis identified MAD2 mitotic arrest deficient-like 1 (MAD2L1) mRNA as possible target of miR$192-5 p$, as already reported in the literature (Georges et al. 2008) (Fig. 2, panel a). MAD2L1 mRNA expression was up-regulated in children with $\mathrm{CD}$, with a threefold increase in Marsh 3C patients compared to controls (0.72 \pm 0.60 , $1.72 \pm 1.07$ and $2.12 \pm 1.33$ in controls, Marsh $3 \mathrm{AB}$ and Marsh 3C, respectively, $p<0.05$ by ANOVA) (Fig. 2, panel b). This finding was present only in children, since in adult CD subjects mRNA levels were comparable to controls $(1.56 \pm 1.07,1.86 \pm 0.98$ and $1.94 \pm 1.05$ in controls, Marsh $3 \mathrm{AB}$ and Marsh 3C, respectively; data not shown). MAD2L1 protein expression paralleled mRNA expression: its level was up-regulated in CD patients, in particular in Marsh $3 \mathrm{C}$ subjects $(0.56 \pm 0.32,0.78 \pm 0.34$ and $2.55 \pm 1.71$, controls, Marsh $3 \mathrm{AB}$ and Marsh 3C, respectively, $p<0.05$ ANOVA) (Fig. 2, panel c, d).

In our previous study, we found that other miRNAs (miR-31-5p and miR-338-3p) were down-regulated in the duodenum of adults CD patients. miR-31-5p was significantly down-regulated in $\mathrm{CD}(1.02 \pm 0.38$ in controls, $0.19 \pm 0.08$ in Marsh 3AB and $0.40 \pm 0.16$ in Marsh 3C, ANOVA vs controls $p<0.05$ both) (Fig. 1). Furthermore, increased mRNA expression of its target forkhead box P3 (FOXP3) was detected in Marsh 3C, with 4.3 times higher levels compared to controls $(4.37 \pm 2.48$ vs $7.46 \pm 7.55$ and $18.92 \pm 21.75$ in controls, Marsh $3 \mathrm{AB}$ and Marsh $3 \mathrm{C}$, respectively, $p=0.005$ by ANOVA) (Fig. 3, panel a). FOXP3 protein expression was similar to mRNA expression, being up-regulated in marsh 3C patients compared to controls $(1.88 \pm 0.49$ and $3.94 \pm 0.89$, controls and Marsh 3C respectively, $p=0.012$ by ANOVA) (Fig. 3, panel b, c).
We then analyzed miR-338-3p expression; also in this case, miR-338-3p was significantly down-regulated in CD patients compared to controls, in particular in Marsh $3 \mathrm{C}$ patients $(0.62 \pm 0.28,0.37 \pm 0.31$ and $0.29 \pm 0.21$, in controls, Marsh 3AB and Marsh 3C, respectively. $p<0.05$, ANOVA) (Fig. 1). We also evaluated its putative target, runt-related transcription factor 1 (RUNX1); similarly to FOXP3, it was significantly up-regulated in Marsh $3 \mathrm{C}$ patients compared to controls, with a fourfold increase $(0.51 \pm 0.42$ in controls and $2.01 \pm 1.42$ in Marsh $3 \mathrm{C}$, $p<0.05$ ) (Fig. 3 panel d).

Other miRNAs can be involved in the regulation of the immune response in celiac duodenum; another possible candidate is miR-21-5p, which has been previously reported as involved in inflammatory and immune response, in particular being able to stimulate cytokine expression (Schetter et al. 2009; Zhang et al. 2015).

We detected a significant up-regulation of miR-21-5p expression in Marsh 3C patients (1.30 $\pm 0.41,1.65 \pm 1.41$ and $2.41 \pm 0.73$ in controls, Marsh $3 \mathrm{AB}$ and Marsh $3 \mathrm{C}$, respectively, $p<0.05$ by ANOVA). Since the processing of miRNAs leads to the generation of two mature forms, we also wanted to assess whether miR-21-3p had the same trend and we observed an up-regulation in Marsh 3C patients, with a twofold increase compared to controls $(2.54 \pm 0.51,3.15 \pm 2.66$ and $5.59 \pm 1.77$ in controls, Marsh $3 \mathrm{AB}$ and Marsh 3C, respectively, $p<0.05$ by ANOVA) (Fig. 1). In silico analysis of possible targets of miR-21-5p revealed a binding site for this miRNA on $3^{\prime}$ UTR of programmed cell death 4 (PDCD4) (Shen et al. 2014); nevertheless, we did not detect any correlation, since PDCD4 mRNA showed an increase in CD patients compared to controls, although not significant $(1.48 \pm 0.69,2.10 \pm 1.26$ and $2.84 \pm 2.26$ in controls, Marsh 3AB and Marsh 3C, respectively) (data not shown).

Among other possible targets of miR-21-5p, we analyzed signal transducer and activator of transcription 3 (STAT3) (Kim et al. 2012). In this case, we observed a significant increase in STAT3 mRNA in CD patients, with 2.4 times higher expression in Marsh 3C patients $(1.23 \pm 1.30,2.04 \pm 0.79$ and $3.36 \pm 1.54$ in controls, Marsh 3AB and Marsh 3C, respectively, $p<0.05$ by ANOVA) (Fig. 4, panel a). However, the relationship between miR-21 and STAT3 could be complex, since STAT3 can cause the transcriptional activation of miR-21 (Kohanbash and Okada 2012). We thus evaluated STAT3 phosphorylation, detecting an increase in serine 727 phosphorylation in $\mathrm{CD}$ patients, although not significant $(0.86 \pm 0.36$ vs $1.42 \pm 1.08$ in controls and Marsh $3 \mathrm{C}$, respectively) (Fig. 4 panel b, c).

We then assessed the circulating levels of the miRNAs described above in the plasma of CD patients at diagnosis or on gluten-free diet (GFD) (Fig. 5). miR-192-5p 

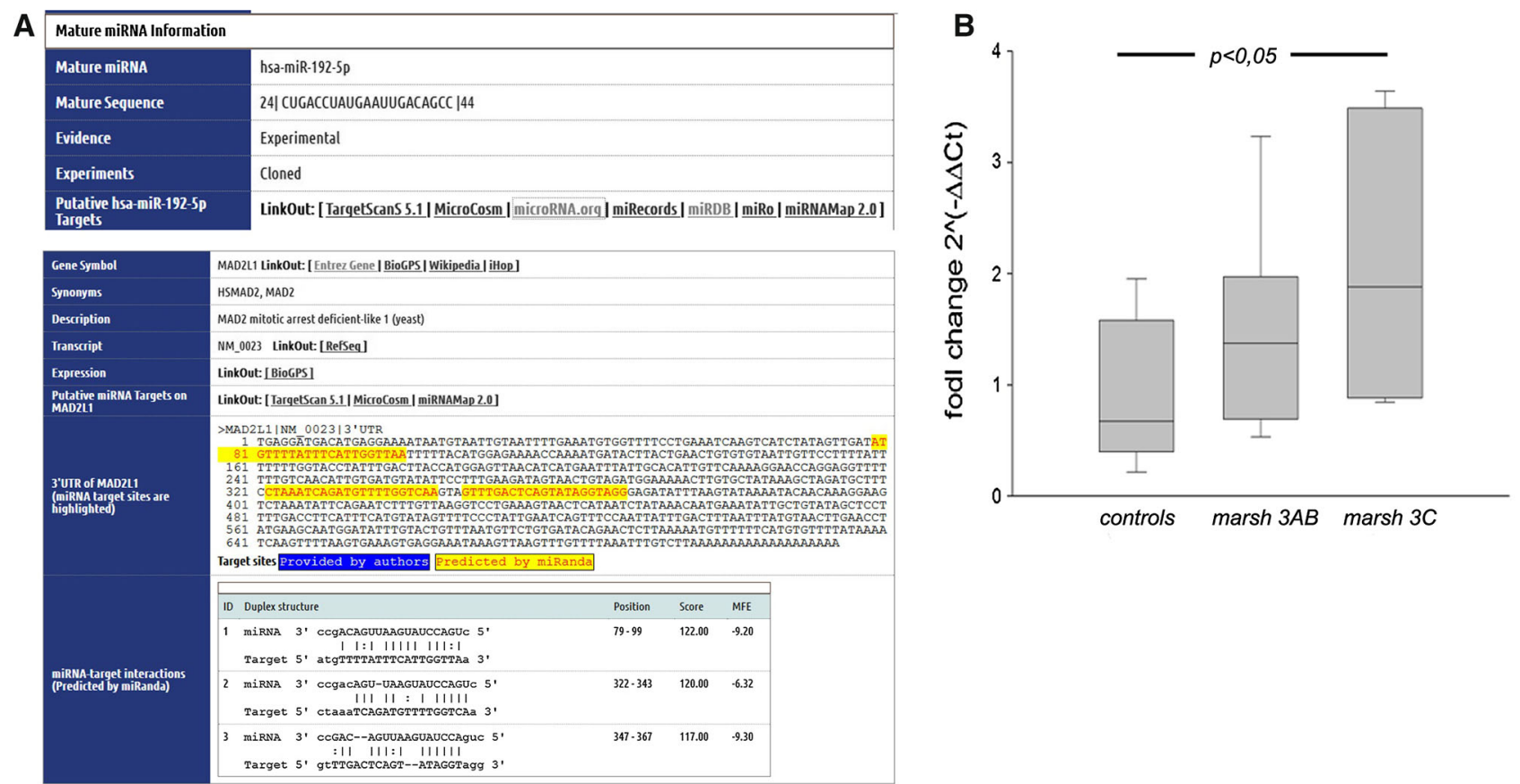

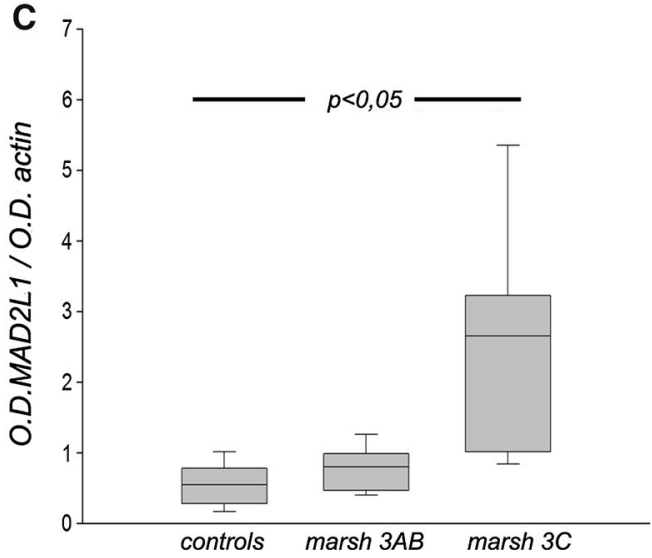

Fig. 2 MAD2L1 mRNA and protein expression. a Alignment between miR-192-5p and predicted target MAD2L1 using miRTarBase software. b Expression level of MAD2L1 mRNA in duodenal biopsies of controls $(n=8)$, Marsh 3AB $(n=8)$ and Marsh 3C $(n=12)$ celiac pediatric patients. Data obtained by quantitative PCR are represented as fold chance compared to an external sample. The

expression showed a significant reduction in $\mathrm{CD}$ patients at diagnosis, Marsh $3 \mathrm{AB}(0.32 \pm 0.14)$ and Marsh 3C patients $(0.35 \pm 0.19)$ compared to controls $(1.14 \pm 0.36)$ ( $p<0.05$ with ANOVA test, both), but in GFD patients it did not reach a level comparable to controls $(0.24 \pm 0.14$, $p=0.001$ ) (Fig. 5, panel a). miR-486-5p showed an upregulation trend, as detected in biopsies, but it was not significant. Furthermore, the analysis of GFD plasma revealed an expression level still higher than controls $(2.04 \pm 1.16,3.79 \pm 3.29,3.66 \pm 2.66$ and $4.18 \pm 1.57$ in controls, Marsh 3AB, Marsh 3C and GFD, respectively) (Fig. 5, panel b). miR-31-5p in plasma of CD patients at box plots show median value and the 25 and 75 percentiles, whiskers the maximum and minimum value. Statistical analysis was performed by ANOVA. c Densitometric analysis of MAD2L1 protein in duodenal biopsies of celiac patients and controls normalized on actin expression ( $n=7$ controls, $\mathrm{n}=8$ Marsh $3 \mathrm{AB}$ and $n=8$ Marsh $3 \mathrm{C}$ ) and $\mathbf{d}$ western blot image of MAD2L1 and actin levels in controls and CD patients

diagnosis showed a significantly decrease in Marsh $3 \mathrm{AB}$ $(0.27 \pm 0.12)$ and $3 \mathrm{C}$ patients $(0.43 \pm 0.25)$ compared to controls $(0.71 \pm 0.26, p=0.004$ and 0.003 for Marsh $3 \mathrm{AB}$ and $3 \mathrm{C}$, respectively). Moreover, the difference between controls and GFD levels $(0.59 \pm 0.35)$ resulted not statistically significant (Fig. 5, panel c). miR-21-5p trend in plasma was comparable to biopsies, and in Marsh $3 \mathrm{C}$ patients its levels were 3 times higher than controls $(1.18 \pm 0.64,1.24 \pm 0.15$ and $3.90 \pm 1.79$ in controls, Marsh $3 \mathrm{AB}$ and $3 \mathrm{C}$, respectively, $p<0.05$ by ANOVA). GFD patients showed a decrease in miR-21-5p, and the difference in expression levels of GFD compared to 

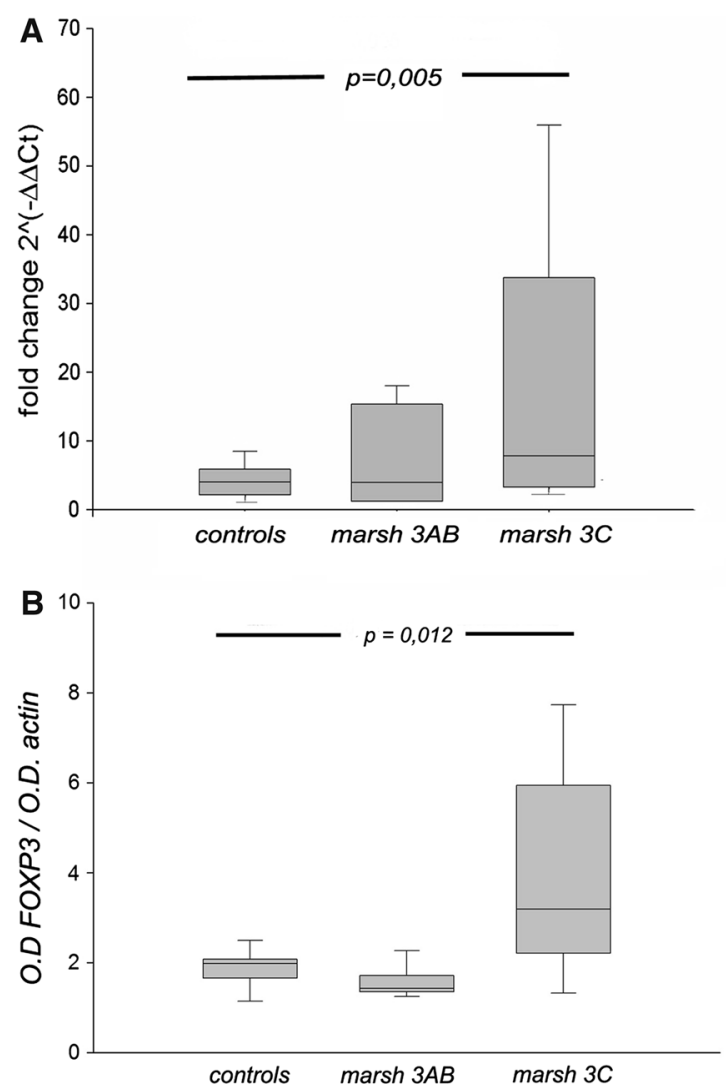

Fig. 3 FOXP3 mRNA and protein, and RUNX1 mRNA expression. a Expression level of FOXP3 mRNA in duodenal biopsies of controls $(n=8)$, Marsh $3 \mathrm{AB}(n=8)$ and Marsh $3 \mathrm{C}(n=12)$ celiac pediatric patients. Data obtained by quantitative PCR are represented as fold change compared to an external sample. The box plots show median value and the 25 and 75 percentiles, whiskers the maximum and minimum value. Statistical analysis was performed by ANOVA. b western blot image of FOXP3 and actin levels in controls and CD

controls, resulted not statistically significant (Fig. 5, panel d). Finally, miR-21-3p showed a trend similar to that detected in biopsies: $0.82 \pm 0.38$ (controls), $1.80 \pm 1.60$ (Marsh 3AB), $1.98 \pm 2.03$ (Marsh 3C), but the results were not statistically significant; however, GFD group showed expression levels similar to controls $(0.52 \pm 0.12)$ (Fig. 5, panel e). Results obtained in plasma in GFD patients are also summarized in Table $2 \mathrm{~S}$ ).

\section{Discussion}

The present study shows that the pattern of expression of some miRNAs and related gene targets in the duodenal mucosa of pediatric patients with $\mathrm{CD}$ differs from that observed in controls or adults celiac patients.

In a previous study (Magni et al. 2014), we detected, in adult CD patients, down-regulated miRNAs associated with the up-regulation of molecules involved in innate or adaptive immunity.
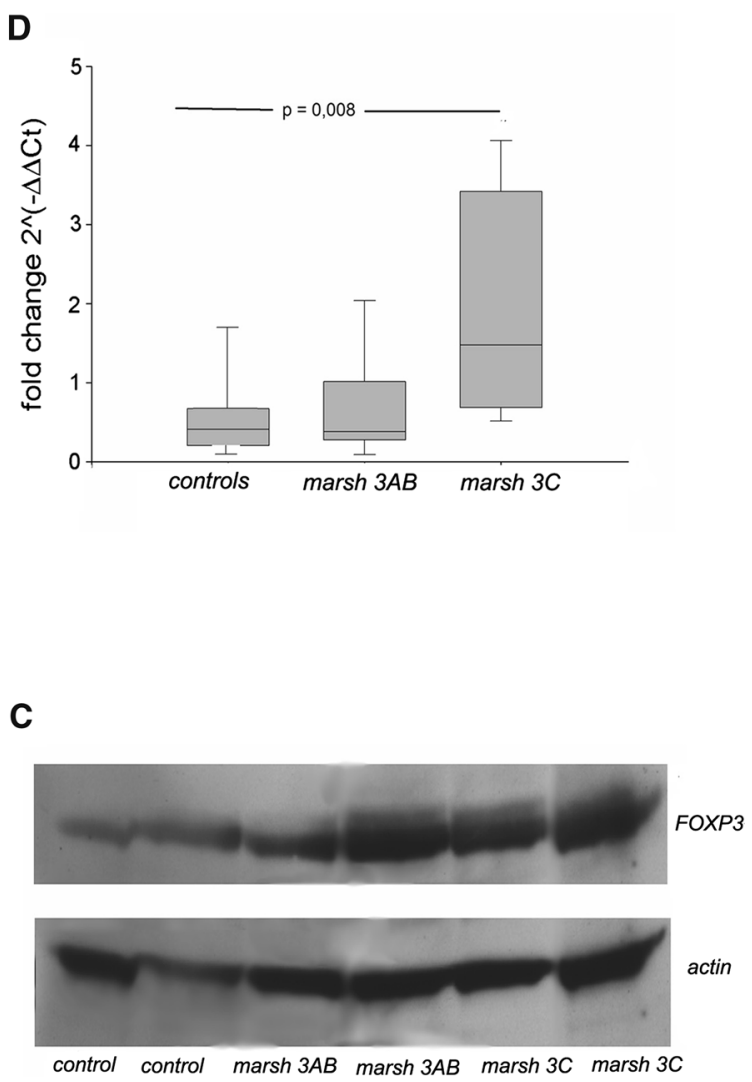

patients and $\mathbf{c}$ densitometric analysis of FOXP3 protein in duodenal biopsies of celiac patients and controls normalized on actin expression ( $n=7$ controls, $n=7$ Marsh $3 \mathrm{AB}$ and $n=8$ Marsh 3C). d Expression level of RUNX1 mRNA in duodenal biopsies of controls $(n=8)$, Marsh $3 \mathrm{AB}(n=8)$ and Marsh $3 \mathrm{C}(n=12)$ celiac pediatric patients. Data obtained by quantitative PCR are represented as fold chance compared to an external sample and statistical analysis performed by ANOVA

We demonstrate that also in pediatric CD patients, miR192-5p was down-regulated with a major decrease in Marsh 3C patients; however, when we analyzed the hypothetical targets of this miRNA, NOD2 and CXCL2, we could not detect an inverse correlation either with mRNA or protein expression levels.

NOD2 is a member of pattern recognition receptors, which plays an important role in immune response at the mucosal level, recognizing peptidoglycan of the bacterial membrane and activating the NF-kB pathway (Carneiro et al. 2008). CXCL2 is a chemokine produced by epithelial intestinal cells (Ohtsuka and Sanderson 2003) and secreted by monocytes and macrophages after activation of TollLike Receptors (TLRs) (Areschoug and Gordon 2008). Both proteins could have a role in the pathogenesis of $\mathrm{CD}$, since they are strictly correlated with the immune response and/or tolerance to antigens. Despite these evidences, we did not observe any variation in their protein expression in pediatric CD patients compared to controls. The unchanged levels of both proteins could be explained by the action of 

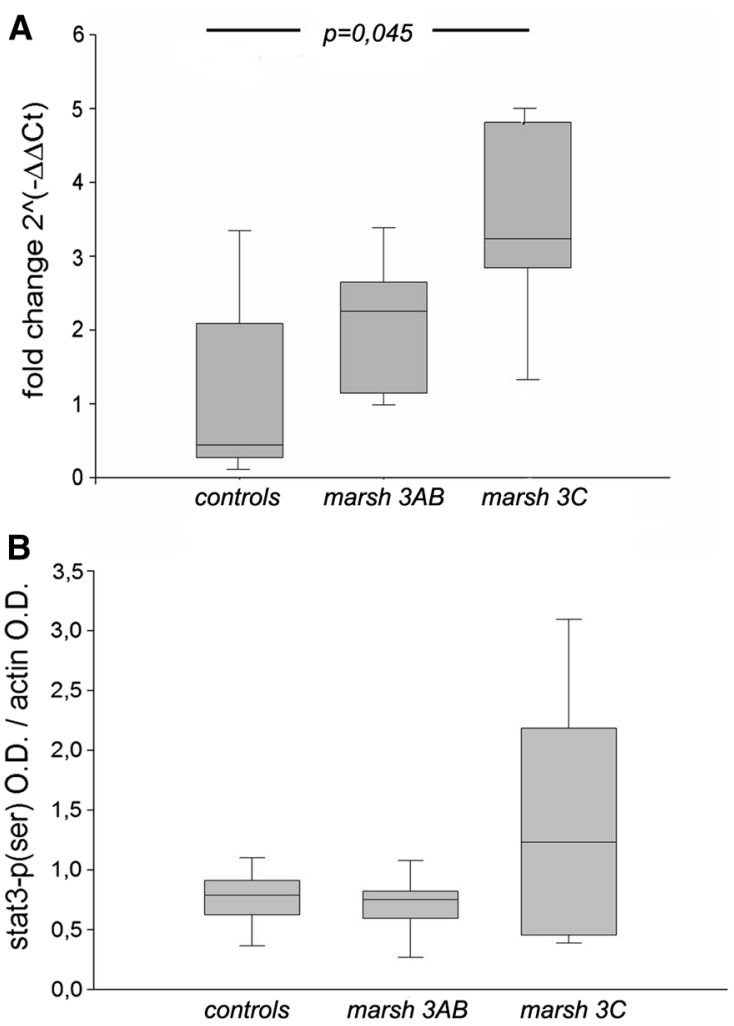

Fig. 4 STAT3 mRNA and phosphorylated protein expression. a Expression level of STAT3 mRNA in duodenal biopsies of controls $(n=8)$, Marsh $3 \mathrm{AB}(n=8)$ and Marsh $3 \mathrm{C}(n=12)$ celiac pediatric patients. Data obtained by quantitative PCR are represented as fold change compared to an external sample. The box plots show median

other miRNAs, since several binding sites for various miRNAs are present in the $3^{\prime}$ UTR of these two mRNAs. In silico analyses revealed NOD2 and CXCL2 as target genes of miR-486-5p, involved in gastrointestinal diseases (Zhu et al. 2014) and in the development of the gut (Liang et al. 2014). In our cohort it was up-regulated in pediatric CD patients; we thus speculate that the expression of miR-486$5 p$ could contrast the action of miR-192-5p on NOD2 and CXCL2 in the pediatric gut, in CD patients. Interestingly, no variation in miR-486-5p expression was observed in adult $\mathrm{CD}$ patients, further supporting the hypothesis of a different miRNA regulation in children.

The development of the intestinal immune system starts in early natal life (Steege et al. 1997), and the postnatal period is a critical window for maturation, since the microbiota composition diverges from the maternal one (Donovan et al. 2014). Hornef and Fulde (2014), showed the differential expression of immunity genes in the murine neonate and adult intestine, and age-related transformations have also been reported for adaptive immunity (Howie et al. 1998; He et al. 2013). All these findings support the idea that the gut (and its immune system) shows gene expression changes clearly related to age (Lee et al. 2001;

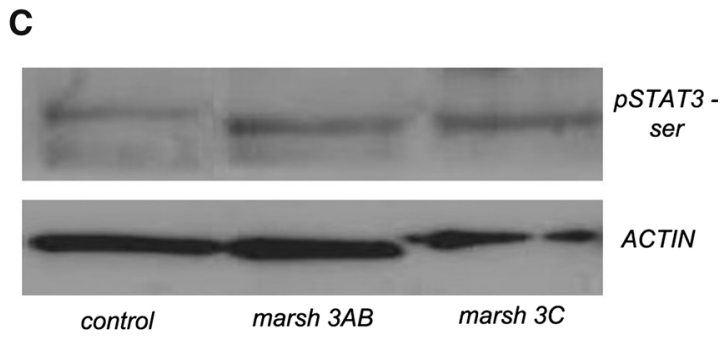

value and the 25 and 75 percentiles, whiskers the maximum and minimum value. Statistical analysis was performed by ANOVA. b Western blot image of STAT3 phosphorylated on serine 727 and actin levels in controls and CD patients and $\mathbf{c}$ relative densitometric analysis ( $n=7$ controls, $n=7$ Marsh $3 \mathrm{AB}$ and $n=8$ Marsh 3C)

Steegenga et al. 2012), modifications that could be controlled by specific miRNA patterns. In celiac disease a variation in proteins of the innate immune system could be part of the complex relationship among innate immunity, microbiota and food tolerance. NOD2 can mediate the degree of inflammation in the intestinal mucosa caused by an alteration of the microbiota, as demonstrated in NOD2 ko mice (Ramanan et al. 2014). However, the alteration of the microbiota itself could depend on the absence of NOD2 protein (Rehman et al. 2011) and, in turn, variation in the microbiota could affect the processing of peptides (including those of gliadin). In fact the presence of a dysbiosis has been reported in CD (Collado et al. 2009) and has also been related to the presence of symptoms in patients on GFD (Sánchez et al. 2011).

Conversely, we noticed variations in another verified target of miR-192-5p, MAD2L1 (Georges et al. 2008), implicated in the checkpoint that monitors proper chromosome attachment to spindle microtubules during cell division (Skinner et al. 2008). In presence of an abnormal metaphase alignment, it converts its inactive open form in the active close one and links Bub1-related kinase (BubR1) and cell division cycle $20(\mathrm{Cdc} 20)$ proteins, inhibiting cell 

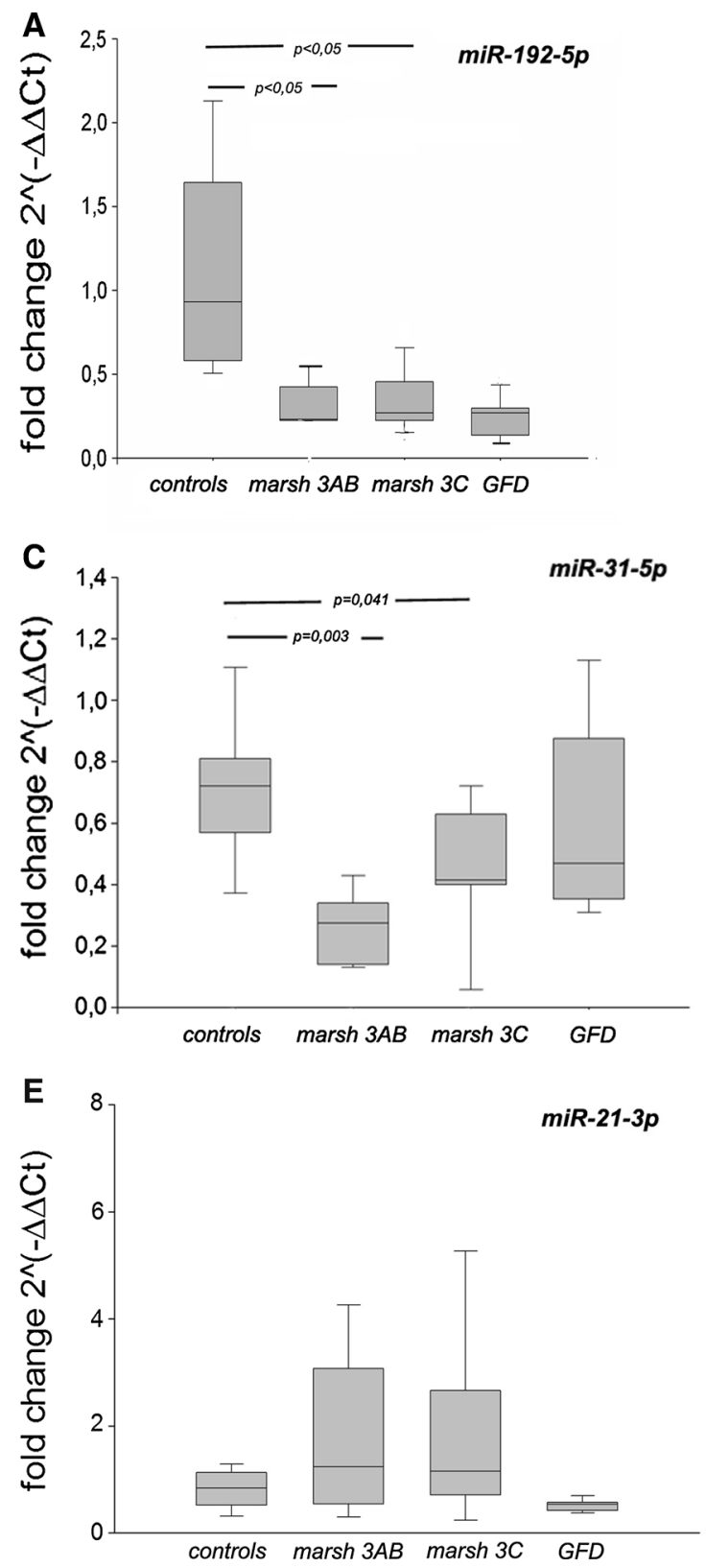

Fig. 5 miRNAs expression in plasma samples. Expression level of miR-192-5p, miR-31-5p, miR-21-5p, miR-21-3p and miR-486-5p in plasma samples of controls $(n=12)$, Marsh 3AB $(n=7)$, Marsh 3C $(n=10)$ and GFD $(n=7)$ celiac pediatric patients. Data obtained by

cycle progression (Han et al. 2013). In ulcerative colitis, MAD2L1 protein expression was increased as compared to controls (Burum-Auensen et al. 2007), whereas its mRNA overexpression was detected investigating gene expression profile in mucosa of $\mathrm{CD}$ pediatric patients (Bragde et al. 2011). Since this protein causes cell cycle arrest (Wassmann and Benezra 2001), its increased expression could be interpreted as an attempt to control anomalous processes of cell replication that may be present in the intestine of pediatric CD patients.
B
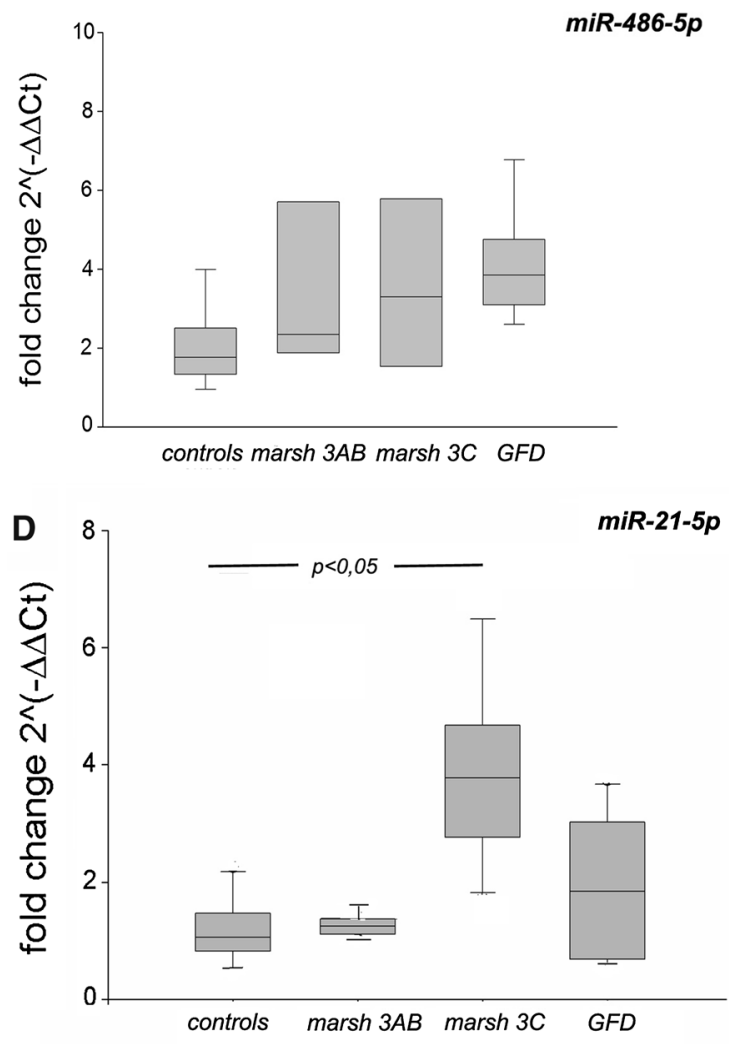

quantitative PCR are represented as fold change compared to an external sample. The box plots show median value and the 25 and 75 percentiles, whiskers the maximum and minimum value. Statistical analysis was performed by one-way ANOVA

Also miR-21-5p could have a role in the regulation of innate immunity and/or inflammation; in fact, in silico analysis of possible targets of miR-21-5p, revealed a binding site on the $3^{\prime} \mathrm{UTR}$ of STAT3 (Kim et al. 2012). In our previous study, miR-21-5p did not show any variations in its expression in duodenal biopsies of adult $\mathrm{CD}$ patients compared to controls (Magni et al. 2014), whereas in children we detected a significant increase in miR-21-5p in the duodenal biopsies of Marsh 3C CD patients, which was paralleled by an increase in STAT3 mRNA expression, fact 
that does not agree with a direct effect of miR-21-5p on STAT3. However, it has been demonstrated that the connection between them could be complex, since STAT3 is responsible for the transcriptional activation of miR-21-5p (Kohanbash and Okada 2012; Löffler et al. 2007; Han et al. 2012). STAT3 plays a major role in inflammation, and Musso et al. (2005), described an involvement of STAT3 in inflammatory bowel disease and celiac disease, in areas of active inflammation and infiltrating macrophages. STAT3 is targeted by miR-21-5p, but its role as a transcription factor could prevail on the miRNA inhibitory effect, thus enhancing miR-21-5p transcription. In fact, in CD patients, STAT3 phosphorylation on serine 727, which is responsible for STAT3 activity as a transcriptional factor, was increased (Yokogami et al. 2000). Since STAT3 is a gene regulated by interleukin-6 (IL-6) and interleukin-15 (IL15) pathways (Sarra et al. 2013), we speculate that in pediatric patients with $\mathrm{CD}$, the activation of inflammation/ innate immunity induces STAT3 activity.

As regards the other miRNAs, we detected a significant down-regulation of miR-31-5p and an up-regulation of its target, FOXP3, transcription factor essential for Treg development (Rouas et al. 2009), which represents a pivotal event in the regulation of the immune response also in CD (Brazowski et al. 2010). Similarly, we observed a down-regulation of miR-338-3p in pediatric Marsh 3C patients which inversely correlated with its target RUNX1, an activator factor of FOXP3 transcription (Ono et al. 2007). Both these genes have a role in the regulation of intestinal adaptive immunity, and the results are similar to those observed in adult CD patients (Magni et al. 2014), suggesting that their activation could depend on local stimuli rather than on pure age-related changes.

The identification of a panel of miRNAs that could be used as a diagnostic/follow-up tool surely could be extremely useful, in particular in pediatric patients. For this reason we analyzed miRNAs expression in plasma. Results showed the same trend of duodenal biopsies; miR-192-5p and miR-31-5p decreased in $\mathrm{CD}$ patients compared to controls, consistently with the severity of mucosal damage; similarly, miR-21-5p and miR-21-3p increased their expression even though miR-21-3p did not reach statistical significance. We were unable to detect miR-338-3p in plasma, probably due to very low expression of this miRNA in the samples. However, when we evaluated in the whole cohort the biopsy-plasma pairs, we did not detect a significant positive correlation, thus suggesting the presence of other factors (or sources) determining the circulating level of each miRNA.

In GFD patients, miR-192-5p and 486-5p expression in plasma did not return to levels comparable to controls, in fact they remained significantly down-regulated. For miR-31-5p, 21-5p and 21-3p in GFD, indeed, expression levels tended to return to controls levels and the difference in expression between the two groups resulted not statistically significant (Table 2S). GFD patients were comparable to untreated ones in terms of HLA typing and had undergone GFD for at least 12 months; although we could not obtain a second biopsy to verify the level of inflammation, all biochemistry tests were negative, and interviews confirmed a good adhesion to the diet. However, negative antibodies titer may not be a perfect predictor of mucosal healing in the first years after diagnosis (Vécsei et al. 2014). Thus, the lack of normalization of miRNA levels will need further investigation, both evaluating biopsy expression levels (if available) as well as possible polymorphisms in $\mathrm{CD}$ patients able to affect their expression levels.

Taken together, these data suggest that a wider panel of plasmatic miRNAs should be analyzed to provide reliable information on the intestinal mucosa status and, possibly, reduce the need for invasive procedures.

Acknowledgments We would like to thank Dr. Maria Teresa Bardella for the clinical characterization of the adult CD patients. Funding was provided by Research Funds (FAR) from University of Milano Bicocca (DB).

\section{Compliance with ethical standards}

Conflict of interest Gaia Buoli Comani, Roberto Panceri, Marco Dinelli, Andrea Biondi, Clara Mancuso, Raffaella Meneveri and Donatella Barisani declare that they have no conflict of interest.

Ethical approval All procedures performed in studies involving human participants were in accordance with the ethical standards of the institutional research committee and with the 1964 Helsinki declaration and its later amendments or comparable ethical standards.

Informed consent Informed consent was obtained from all individual participants, or their parents if children, included in the study.

\section{References}

Areschoug T, Gordon S (2008) Pattern recognition receptors and their role in innate immunity: focus on microbial protein ligands. Contrib Microbiol 15:45-60

Bragde H, Jansson U, Jarlsfelt I, Söderman J (2011) Gene expression profiling of duodenal biopsies discriminates celiac disease mucosa from normal mucosa. Pediatr Res 69:530-537

Brazowski E, Cohen S, Yaron A, Filip I, Eisenthal A (2010) FOXP3 expression in duodenal mucosa in pediatric patients with celiac disease. Pathobiology 77:328-334

Burum-Auensen E, Deangelis PM, Schjølberg AR, Røislien J, Andersen SN, Clausen OP (2007) Spindle proteins Aurora A and BUB1B, but not Mad2, are aberrantly expressed in dysplastic mucosa of patients with longstanding ulcerative colitis. J Clin Pathol 60:1403-1408

Carneiro LA, Magalhaes JG, Tattoli I, Philpott DJ, Travassos LH (2008) Nod-like proteins in inflammation and disease. J Pathol 204:136-148 
Collado MC, Donat E, Ribes-Koninckx C, Calabuig M, Sanz Y (2009) Specific duodenal and faecal bacterial groups associated with paediatric coeliac disease. J Clin Pathol 62:264-269

Diamanti A, Capriati T, Basso MS, Panetta F, Di Ciommo Laurora VM, Bellucci F, Cristofori F, Francavilla R (2014) Celiac disease and overweight in children: an update. Nutrients 6:207-220

Donovan SM, Wang M, Monaco MH, Martin CR, Davidson LA, Ivanov I, Chapkin RS (2014) Noninvasive molecular fingerprinting of host-microbiome interactions in neonates. FEBS Lett 588:4112-4119

Dubois PC, Trynka G, Franke L, Hunt KA, Romanos J, Curtotti A, Zhernakova A, Heap GA, Adány R, Aromaa A, Bardella MT, van den Berg LH, Bockett NA, de la Concha EG, Dema B, Fehrmann RS, Fernández-Arquero M, Fiatal S, Grandone E, Green PM, Groen HJ, Gwilliam R, Houwen RH, Hunt SE, Kaukinen K, Kelleher D, Korponay-Szabo I, Kurppa K, MacMathuna P, Mäki M, Mazzilli MC, McCann OT, Mearin ML, Mein CA, Mirza MM, Mistry V, Mora B, Morley KI, Mulder CJ, Murray JA, Núñez C, Oosterom E, Ophoff RA, Polanco I, Peltonen L, Platteel M, Rybak A, Salomaa V, Schweizer JJ, Sperandeo MP, Tack GJ, Turner G, Veldink JH, Verbeek WH, Weersma RK, Wolters VM, Urcelay E, Cukrowska B, Greco L, Neuhausen SL, McManus R, Barisani D, Deloukas P, Barrett JC, Saavalainen P, Wijmenga C, van Heel DA (2010) Multiple common variants for celiac disease influencing immune gene expression. Nat Genet 42:295-302

Georges SA, Biery MC, Kim SY, Schelter JM, Guo J, Chang AN, Jackson AL, Carleton MO, Linsley PS, Cleary MA, Chau BN (2008) Coordinated regulation of cell cycle transcripts by p53Inducible microRNAs, miR-192 and miR-215. Cancer Res 68:0105-0112

Giersiepen K, Lelgemann M, Stuhldreher N, Ronfani L, Husby S, Koletzko S, Korponay-Szabó IR, ESPGHAN Working Group on Coeliac Disease Diagnosis (2012) Accuracy of diagnostic antibody tests for coeliac disease in children: summary of an evidence report. J Pediatr Gastroenterol Nutr 54:229-241

Gutierrez-Achury J, Zhernakova A, Pulit SL, Trynka G, Hunt KA, Romanos J, Raychaudhuri S, van Heel DA, Wijmenga C, de Bakker PI (2015) Fine mapping in the MHC region accounts for $18 \%$ additional genetic risk for celiac disease. Nat Genet 47:577-578

Han L, Yue X, Zhou X, Lan FM, You G, Zhang W, Zhang KL, Zhang CZ, Cheng JQ, Yu SZ, Pu PY, Jiang T, Kang CS (2012) MicroRNA-21 expression is regulated by $\beta$-catenin/STAT3 pathway and promotes glioma cell invasion by direct targeting RECK. CNS Neurosci Ther 18:573-583

Han JS, Holland AJ, Fachinetti D, Kulukian A, Cetin B, Cleveland DW (2013) Catalytic assembly of the mitotic checkpoint inhibitor BubR1-Cdc20 by a Mad2-induced functional switch in Cdc20. Mol Cell 51:92-104

He Q, Morillon YM 2nd, Spidale NA, Kroger CJ, Liu B, Sartor RB, Wang B, Tisch R (2013) Thymic development of autoreactive T cells in NOD mice is regulated in an age-dependent manner. J Immunol 191:5858-5866

Hornef MW, Fulde M (2014) Ontogeny of intestinal epithelial innate immune responses. Front Immunol 5:474

Howie D, Spencer J, DeLord D, Pitzalis C, Wathen NC, Dogan A, Akbar A, MacDonald TT (1998) Extrathymic T cell differentiation in the human intestine early in life. $\mathrm{J}$ Immunol 161:5862-5872

Husby S, Koletzko S, Korponay-Szabó IR, Mearin ML, Phillips A, Shamir R, Troncone R, Giersiepen K, Branski D, Catassi C, Lelgeman M, Mäki M, Ribes-Koninckx C, Ventura A, Zimmer KP, ESPGHAN Working Group on Coeliac Disease Diagnosis, ESPGHAN Gastroenterology Committee, European Society for
Pediatric Gastroenterology, Hepatology, and Nutrition (2012) ESPGHAN guidelines for the diagnosis of celiac disease in children and adolescents: an evidence-based approach. J Pediatr Gastroenterol Nutr 54:136-160

Kenrick K, Day AS (2014) Coeliac disease: Where are we in 2014? Aust Fam Physician 43:674-678

Kim YJ, Hwang SH, Cho HH, Shin KK, Bae YC, Jung JS (2012) MicroRNA 21 regulates the proliferation of human adipose tissue-derived mesenchymal stem cells and high-fat diet-induced obesity alters microRNA 21 expression in white adipose tissues. J Cell Physiol 227:183-193

Kohanbash G, Okada H (2012) MicroRNA and STAT interplay. Semin Cancer Biol 22:70-75

Lee HM, Greeley GH Jr, Englander EW (2001) Age-associated changes in gene expression patterns in the duodenum and colon of rats. Mech Ageing Dev 122:355-371

Liang G, Malmuthuge N, McFadden TB, Bao H, Griebel PJ, Stothard P, le Guan L (2014) Potential regulatory role of microRNAs in the development of bovine gastrointestinal tract during early life. PLoS ONE 9:e92592

Lionetti E, Castellaneta S, Francavilla R, Pulvirenti A, Tonutti E, Amarri S, Barbato M, Barbera C, Barera G, Bellantoni A, Castellano E, Guariso G, Limongelli MG, Pellegrino S, Polloni C, Ughi C, Zuin G, Fasano A, Catassi C, SIGENP (Italian Society of Pediatric Gastroenterology, Hepatology, and Nutrition) Working Group on Weaning and CD Risk (2014) Introduction of gluten, HLA status, and the risk of celiac disease in children. N Engl J Med 371:1295-1303

Löffler D, Brocke-Heidrich K, Pfeifer G, Stocsits C, Hackermüller J, Kretzschmar AK, Burger R, Gramatzki M, Blumert C, Bauer K, Cvijic H, Ullmann AK, Stadler PF, Horn F (2007) Interleukin-6 dependent survival of multiple myeloma cells involves the Stat3mediated induction of microRNA-21 through a highly conserved enhancer. Blood 110:1330-1333

Mabbott NA, Kobayashi A, Sehgal A, Bradford BM, Pattison M, Donaldson DS (2015) Aging and the mucosal immune system in the intestine. Biogerontology 16:133-145

Magni S, Buoli Comani G, Elli L, Vanessi S, Ballarini E, Nicolini G, Rusconi M, Castoldi M, Meneveri R, Muckenthaler MU, Bardella MT, Barisani D (2014) miRNAs affect the expression of innate and adaptive immunity proteins in celiac disease. Am J Gastroenterol 109:1662-1674

Musso A, Dentelli P, Carlino A, Chiusa L, Repici A, Sturm A, Fiocchi C, Rizzetto M, Pegoraro L, Sategna-Guidetti C, Brizzi MF (2005) Signal transducers and activators of transcription 3 signaling pathway: an essential mediator of inflammatory bowel disease and other forms of intestinal inflammation. Inflamm Bowel Dis 11:91-98

Oberhuber G (2000) Histopathology of celiac disease. Biomed Pharmacother 54:368-372

Ohtsuka Y, Sanderson IR (2003) Dextran sulfate sodium-induced inflammation is enhanced by intestinal epithelial cell chemokine expression in mice. Pediatr Res 53:143-147

Ono M, Yaguchi H, Ohkura N, Kitabayashi I, Nagamura Y, Nomura T, Miyachi Y, Tsukada T, Sakaguchi S (2007) Foxp3 controls regulatory $\mathrm{T}$-cell function by interacting with AML1/Runx1. Nature 446:685-689

Ramanan D, Tang MS, Bowcutt R, Loke P, Cadwell K (2014) Bacterial sensor Nod2 prevents inflammation of the small intestine by restricting the expansion of the commensal Bacteroides vulgatus. Immunity 41:311-324

Rehman A, Sina C, Gavrilova O, Häsler R, Ott S, Baines JF, Schreiber $S$, Rosenstiel P (2011) Nod2 is essential for temporal development of intestinal microbial communities. Gut 60:1354-1362

Ren WY, Wu KF, Li X, Luo M, Liu HC, Zhang SC, Hu Y (2014) Age-related changes in small intestinal mucosa epithelium 
architecture and epithelial tight junction in rat models. Aging Clin Exp Res 26:183-191

Romanos J, Rosén A, Kumar V, Trynka G, Franke L, Szperl A, Gutierrez-Achury J, van Diemen CC, Kanninga R, Jankipersadsing SA, Steck A, Eisenbarth G, van Heel DA, Cukrowska B, Bruno V, Mazzilli MC, Núñez C, Bilbao JR, Mearin ML, Barisani D, Rewers M, Norris JM, Ivarsson A, Boezen HM, Liu E, Wijmenga $C$ (2014) Improving coeliac disease risk prediction by testing non-HLA variants additional to HLA variants. Gut $63: 415-422$

Rouas R, Fayyad-Kazan H, El Zein N, Lewalle P, Rothé F, Simion A, Akl H, Mourtada M, El Rifai M, Burny A, Romero P, Martiat P, Badran B (2009) Human natural Treg microRNA signature: role of microRNA-31 and microRNA-21 in FOXP3 expression. Eur J Immunol 39:1608-1618

Runtsch MC, Round JL, O'Connell MR (2014) MicroRNAs and the regulation of intestinal homeostasis. Front Genet 5:347

Sánchez E, De Palma G, Capilla A, Nova E, Pozo T, Castillejo G, Varea V, Marcos A, Garrote JA, Polanco I, López A, RibesKoninckx C, García-Novo MD, Calvo C, Ortigosa L, Palau F, Sanz Y (2011) Influence of environmental and genetic factors linked to celiac disease risk on infant gut colonization by Bacteroides species. Appl Environ Microbiol 77:5316-5323

Sapone A, Lammers KM, Casolaro V, Cammarota M, Giuliano T, De Rosa M, Stefanile R, Mazzarella G, Tolone C, Russo MI, Esposito P, Ferraraccio F, Cartenì M, Riegler G, de Magistris L, Fasano A (2011) Divergence of gut permeability and mucosal immune gene expression in two gluten-associated conditions: celiac disease and gluten sensitivity. BMC Med 9:23

Sarra M, Cupi ML, Monteleone I, Franzè E, Ronchetti G, Di Sabatino A, Gentileschi P, Franceschilli L, Sileri P, Sica G, Del Vecchio Blanco G, Cretella M, Paoluzi OA, Corazza GR, Pallone F, Monteleone G (2013) IL-15 positively regulates IL-21 production in celiac disease mucosa. Mucosal Immunol 6:244-255

Schetter AJ, Nguyen GH, Bowman ED, Mathé EA, Yuen ST, Hawkes JE, Croce CM, Leung SY, Harris CC (2009) Association of inflammation-related and microRNA gene expression with cancer-specific mortality of colon adenocarcinoma. Clin Cancer Res 15:5878-5887

Schuppan D, Junker Y, Barisani D (2009) Celiac disease: from pathogenesis to novel therapies. Gastroenterology 137:1912-1933

Shen F, Mo MH, Chen L, An S, Tan X, Fu Y, Rezaei K, Wang Z, Zhang L, Fu SW (2014) MicroRNA-21 down-regulates Rb1 expression by targeting PDCD4 in retinoblastoma. J Cancer 5:804-812

Skinner JJ, Wood S, Shorter J, Englander SW, Black BE (2008) The Mad2 partial unfolding model: regulating mitosis through Mad2 conformational switching. J Cell Biol 183:761-768
Steege JC, Buurman WA, Forget PP (1997) The neonatal development of intraepithelial and lamina propria lymphocytes in the murine small intestine. Dev Immunol 5:121-128

Steegenga WT, de Wit NJ, Boekschoten MV, Ijssennagger N, Lute C, Keshtkar S, Bromhaar MM, Kampman E, de Groot LC, Muller M (2012) Structural, functional and molecular analysis of the effects of aging in the small intestine and colon of C57BL/6J mice. BMC Med Genomics 5:38

Telega G, Bennet TR, Werlen S (2008) Emerging new clinical patterns in the presentation of celiac disease. Arch Pediatr Adolesc Med 162:164-168

Vaira V, Roncoroni L, Barisani D, Gaudioso D, Bosari S, Bulfamante G, Doneda L, Conte D, Tomba C, Bardella MT, Ferrero S, Locatelli M, Elli L (2014) microRNA profiles in coeliac patients distinguish different clinical phenotypes and are modulated by gliadin peptides in primary duodenal fibroblasts. Clin Sci 126:417-423

Vécsei E, Steinwendner S, Kogler H, Innerhofer A, Hammer K, Haas OA, Amann G, Chott A, Vogelsang H, Schoenlechner R, Huf W, Vécsei A (2014) Follow-up of pediatric celiac disease: value of antibodies in predicting mucosal healing, a prospective cohort study. BMC Gastroenterol 14:28

Vriezinga SL, Auricchio R, Bravi E, Castillejo G, Chmielewska A, Crespo Escobar P, Kolaček S, Koletzko S, Korponay-Szabo IR, Mummert E, Polanco I, Putter H, Ribes-Koninckx C, Shamir R, Szajewska H, Werkstetter K, Greco L, Gyimesi J, Hartman C, Hogen Esch C, Hopman E, Ivarsson A, Koltai T, Koning F, Martinez-Ojinaga E, te Marvelde C, Pavic A, Romanos J, Stoopman E, Villanacci V, Wijmenga C, Troncone R, Mearin ML (2014) Randomized feeding intervention in infants at high risk for celiac disease. N Engl J Med 371:1304-1315

Wassmann K, Benezra R (2001) Mitotic checkpoints: from yeast to cancer. Curr Opin Genet Dev 11:83-90

Yokogami K, Wakisaka S, Avruch J, Reeves SA (2000) Serine phosphorylation and maximal activation of STAT3 during CNTF signaling is mediated by the rapamycin target mTOR. Curr Biol 10:47-50

Zhang L, Shen J, Cheng J, Fan X (2015) MicroRNA-21 regulates intestinal epithelial tight junction permeability. Cell Biochem Funct 33:235-240

Zhu C, Ren C, Han J, Ding Y, Du J, Dai N, Dai J, Ma H, Hu Z, Shen $\mathrm{H}, \mathrm{Xu} \mathrm{Y}$, Jin G (2014) A five-microRNA panel in plasma was identified as potential biomarker for early detection of gastric cancer. Br J Cancer 110:2291-2299 